\title{
Decline of phosphorus, copper, and zinc in anaerobic swine lagoon columns receiving pretreated influent
}

\author{
Ariel A. Szögi*, Matias B. Vanotti
}

United States Department of Agriculture - Agricultural Research Service - Costal Plains Soil, Water and Plant Research Center, 2611 West Lucas St. - 29501-1242 Florence, SC - USA.

*Corresponding author <ariel.szogi@ars.usda.gov>

Edited by: Airton Kunz

Received June 18, 2015

Accepted August 26, 2015

\begin{abstract}
Land application of both anaerobic lagoon liquid and sludge can increase nutrient accumulation beyond the soil's assimilative capacity and become a threat to water quality in regions with intensive, confined swine production. In a 15-month meso-scale column study, we evaluated the effect of manure pretreatment on the reduction of total suspended solids (TSS), total phosphorus (TP), soluble reactive P (SRP), and total copper $(\mathrm{Cu})$ and zinc $(\mathrm{Zn})$ in swine lagoons using (i) enhanced solid-liquid separation (SS) and (ii) solid-liquid separation plus biological nitrogen treatment with nitrification-denitrification (SS + NDN). A conventional anaerobic lagoon treatment was included as a control. A mass flow balance revealed that with both pretreatments the net mass input of TP, $\mathrm{Cu}$, and $\mathrm{Zn}$ in the lagoon columns declined 80 to $100 \%$ when compared to the control. Even though both pretreatments significantly reduced $\mathrm{P}$ in the inflow, TP and SRP were negatively correlated $(r=-0.51$ to -0.87$)$ with TSS in the liquid fraction because of the dissolution of $\mathrm{P}$ from sludge into the overlying lagoon liquid. On the other hand, the removal of solids by both pretreatments effectively reduced $\mathrm{Cu}$ and $\mathrm{Zn}$ concentrations in the lagoon liquid, and their concentrations were positively correlated $(r=0.79$ to 0.90$)$ with TSS. The decline in mass accumulation of TP, $\mathrm{Cu}$, and $\mathrm{Zn}$ in sludge as a result of the reduction of input solids can help minimize both the frequency of sludge removal for lagoon maintenance and the land area for its disposal.
\end{abstract}

Keywords: pig, manure, nutrients, solid-liquid separation

\section{Introduction}

Confined swine (Sus scrofa L.) production generates large volumes of wastewater typically stored and treated in anaerobic lagoons. These lagoons usually require a sludge maintenance plan consisting of regular sludge removal followed by land application (Barker, 1996). Anaerobic lagoon liquid and sludge are both rich in nutrients, particularly nitrogen $(\mathrm{N})$, phosphorus $(\mathrm{P})$, copper $(\mathrm{Cu})$, and zinc $(\mathrm{Zn})$. However, $\mathrm{P}$ can be the limiting nutrient on land requirements for application of effluent and sludge (Schmidt, 2013). In North Carolina, intensification of swine production and the widespread use of anaerobic lagoons followed by land application of effluents historically increased soil $\mathrm{P}$ beyond crop nutrient needs (Cahoon and Ensign, 2004). Thus, regional accumulation of $\mathrm{P}$ along with $\mathrm{Cu}$ and $\mathrm{Zn}$ in excess of soil assimilative capacity have the potential to pollute water resources through soil leaching or runoff (Nelson et al., 2005; Novak et al., 2000; Novak et al., 2008). An alternative to resolve this environmental problem is the pretreatment of liquid raw manure prior to lagoon input to decrease the $\mathrm{P}, \mathrm{Cu}$ and $\mathrm{Zn}$ land application rates while reducing the frequency and cost of lagoon sludge management.

Solid-liquid separation and nitrification-denitrification are two advanced treatment methods for treating liquid swine manure prior to lagoon input (Szogi et al., 2015). Solid-liquid separation methods are used to divide the liquid and solid fractions of manure by physical and chemical processes (Hjorth et al., 2010). The combination of physical (gravity or mechanical) and chemical (flocculant addition) processes have enhanced the separation efficiency of solids and removal of $\mathrm{P}, \mathrm{Cu}$ and $\mathrm{Zn}$ (Vanotti et al., 2009). On the other hand, the aim of the nitrificationdenitrification process is to biologically transform ammonium $\mathrm{N}$ into innocuous $\mathrm{N}$ gas, and successfully used in advanced wastewater treatment after enhanced solidliquid separation (Vanotti et al., 2005; Vanotti and Szogi, 2008). In a study using experimental lagoon columns, we reported the effect of (i) enhanced solid-liquid separation alone, and (ii) solid-liquid separation plus biological $\mathrm{N}$ pretreatments on water quality, $\mathrm{N}$ losses, and accumulation of $\mathrm{N}$ in swine lagoon sludge (Szogi and Vanotti, 2014). Herein, we report additional new data on $\mathrm{P}, \mathrm{Cu}$ and $\mathrm{Zn}$ concentrations and their mass accumulation in experimental lagoon columns with the objective to better understand the processes occurring in swine lagoons retrofitted with advanced pretreatment technologies.

\section{Materials and Methods}

\section{Experimental set up}

The meso-scale column lagoon study was located in a swine finishing farm in Sampson Co., North Carolina, USA. The column study was set up in the field, adjacent to an anaerobic lagoon retrofitted with a fullscale second-generation wastewater treatment plant that treated the entire waste stream from the swine finishing operation in a multi-step system that included enhanced solid-liquid separation followed by nitrification-denitrification and soluble P removal (Vanotti et al., 2009). 
The lagoon columns were made of 2.1-m length clear polyvinyl chloride pipe (0.153-m i.d.) to replicate the average depth $(2.0 \mathrm{~m})$ of the adjacent anaerobic lagoon (Figure 1). The columns were placed under a carport to simplify the water balance, eliminating the dilution effect from rainfall (Westerman et al., 2010). At the beginning of the experiment, each column received 14.2 $\mathrm{L}$ of sludge and 22.6 L of liquid obtained from the adjacent anaerobic lagoon to replicate the anaerobic lagoon conditions.

Effluents taken from three different points in the treatment plant were used for the meso-scale column lagoon study. Thus, the lagoon column study consisted of the following three treatments: (i) liquid raw manure as the influent of the conventional lagoon treatment (control treatment); (ii) liquid from the flocculant-enhanced solid-liquid separation module (treated raw liquid manure in a one-step process) as the influent for the solid separation lagoon pretreatment (SS pretreatment); and (iii) liquid from the biological $\mathrm{N}$ module (a two-step process of biological $\mathrm{N}$ removal after solid-liquid separation) as the influent for the solid separation plus nitrificationdenitrification lagoon pretreatment (SS + NDN pretreatment). The study was conducted with two lagoon column replicates per treatment.

From each column, a 0.42-L sample was removed weekly at $0.6 \mathrm{~m}$ below the liquid level using a peristaltic

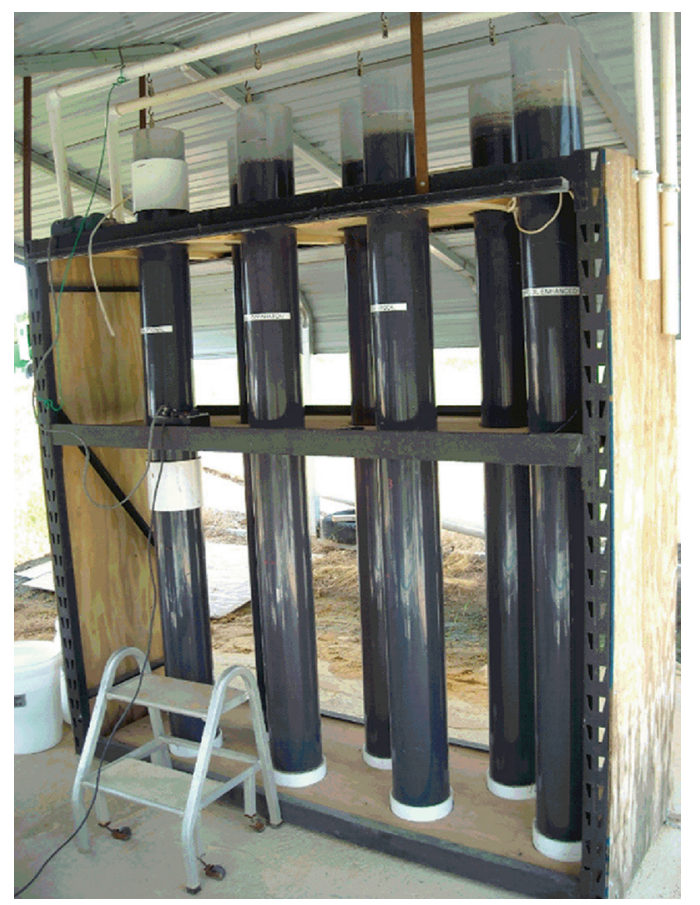

Figure 1 - Meso-scale lagoon column set-up supported with a metal rack. All sides of the metal rack were covered with plywood to maintain the liquid-sludge columns in the dark except for the topmost $0.3 \mathrm{~m}$ of each column, which was exposed to natural light. pump and replaced with the corresponding control or pretreated liquid (Table 1). Tap water was added weekly to each column vessel to replenish evaporation losses.

Once a month, the sludge in each column was gently stirred using a plunger to avoid excessive compaction and to maintain the moderately viscous consistency of the liquid-sludge interface commonly found in anaerobic lagoons (Schmidt, 2013). The plunger was constructed using a flat $0.14-\mathrm{m}$ diameter polyvinyl chloride disc with five perforations attached to a weight placed in the center of the disc. The plunger was slowly lowered from the top of each column into the sludge using a string to stir the sludge for about one minute by slowly moving the plunger up and down. The study lasted approximately 15 months (20 Feb 2007 to 15 May 2008). At the end of the 15-month study, the volumes of supernatant liquid and sludge were measured for each column as described by Szogi and Vanotti (2014).

To verify how closely columns replicated the typical seasonal water temperatures of the anaerobic lagoon, the control treatment column and the adjacent anaerobic lagoon were instrumented with temperature data loggers at $0.5 \mathrm{~m}$ below liquid surface $(\mathrm{HOBO}$, Onset Computer Corp., Bourne, MA). The weekly mean water temperatures of the columns $\left(\mathrm{T}_{\mathrm{C}}\right)$ during the 15 mo-study were highly correlated and very similar to the weekly mean water temperatures of the adjacent full-scale anaerobic lagoon $\left(\mathrm{T}_{\mathrm{AL}}\right)$ such that $\mathrm{T}_{\mathrm{C}}=0.92 * \mathrm{~T}_{\mathrm{AL}}+3.00\left(\mathrm{R}^{2}=0.95\right.$; $p<0.05)$.

\section{Analytical methods}

Wastewater and sludge analyses were performed according to Standard Methods for Examination of Water and Wastewater (APHA, 1998). Total suspended solids (TSS) were determined according to Method $2540 \mathrm{E}$, and $\mathrm{pH}$ was determined electrometrically (Method 4500- $\mathrm{H}^{+}$ $\mathrm{B})$. Total $\mathrm{P}(\mathrm{TP})$ was determined after sulfuric acid digestion and the automated colorimetric method (Szogi and Vanotti, 2009), while soluble reactive P (SRP) was determined using the same colorimetric method after filtration of undigested liquid sample through a $0.45-\mu \mathrm{m}$ membrane filter. Total $\mathrm{Cu}$, and $\mathrm{Zn}$ were determined using nitric acid/ peroxide block digestion (Peters, 2003) and inductively coupled plasma analysis (Method 3125 A).

Table 1 - Composition of the influent liquids in the 15-month column study (means \pm standard deviation, $\mathrm{n}=15$ ).

\begin{tabular}{lcccc}
\hline \multirow{2}{*}{ Component $^{1}$} & \multirow{2}{*}{ Unit } & \multicolumn{3}{c}{ Liquid Manure Pretreatment } \\
\cline { 3 - 5 } & & Control & SS & SS + NDN \\
\hline TSS & $\mathrm{mg} \mathrm{L}^{-1}$ & $13,332 \pm 6802$ & $1382 \pm 732$ & $279 \pm 164$ \\
TP & $\mathrm{mg} \mathrm{L}^{-1}$ & $594 \pm 361$ & $172 \pm 66$ & $97 \pm 24$ \\
SRP & $\mathrm{mg} \mathrm{L}^{-1}$ & $121 \pm 69$ & $103 \pm 46$ & $87 \pm 22$ \\
$\mathrm{Cu}$ & $\mathrm{mg} \mathrm{L}^{-1}$ & $19 \pm 10$ & $2.1 \pm 1.7$ & $0.2 \pm 0.1$ \\
$\mathrm{Zn}$ & $\mathrm{mg} \mathrm{L}^{-1}$ & $29 \pm 13$ & $3.1 \pm 2.1$ & $0.2 \pm 0.2$ \\
$\mathrm{pH}$ & & $7.73 \pm 0.28$ & $7.84 \pm 0.23$ & $7.77 \pm 0.69$ \\
\hline
\end{tabular}

${ }^{1} \mathrm{TSS}=$ total suspended solids; TP $=$ total phosphorus; SRP $=$ soluble reactive phosphorus; ' 2 SS, enhanced solid-liquid separation; SS + NDN, enhanced solidliquid separation plus biological nitrogen 


\section{Mass flow analysis}

A mass flow analysis approach was used for estimating the mass of $\mathrm{P}, \mathrm{Cu}$, and $\mathrm{Zn}$ accumulated in lagoon columns. For each element, the mass flow analysis included the following three components (Figure 2): (i) initial mass (IM) in the column determined at the beginning of the experiment $\left(\mathrm{T}_{0}\right)$; (ii) total mass (TM) expected at the end of the 15-month study ( $\left.\mathrm{T}_{15}\right)$; (iii) the recovered mass (RM) determined at the end of the experiment $\left(\mathrm{T}_{15}\right)$. The TM was estimated as IM plus the mass inflow $\left(M_{\text {in }}\right)$ minus the mass outflow $\left(\mathrm{M}_{\text {out }}\right)$. The mass of each component was calculated as the product of element concentration and the corresponding volume of liquid or sludge. The total element mass in IM, TM and RM of each column was the sum of the element mass in the liquid and sludge fractions. The net mass input (NMI) to each lagoon column was the difference between IM and RM. The ratio TM/RM was used to estimate the percent mass recovery efficiency.

\section{Statistical analysis}

Summary statistics were performed using the PROC MEANS procedure from SAS (Statistical Analysis System, version 9.4). Analysis of variance for the effect of pretreatments on lagoon liquid and sludge chemical compositions was conducted using the GLM model from SAS. Treatment means were compared using the least square difference (LSD) option and were considered different when the probability values were $p<0.05$. Significant relationships between water quality parameters were conducted using the PROC REG linear correlation and regression analysis from SAS.

\section{Results and Discussion}

\section{Effect of pretreatments on water quality}

Concentrations of TSS, TP, SRP, Cu, and $\mathrm{Zn}$ in the liquid of the lagoon columns were monitored during the course of the study for the control and each pretreatment (Figure 3). Each data point is the monthly average of two lagoon columns. The criterion to determine improved water quality was the decline in concentration of TSS, TP, SRP, Cu, and $\mathrm{Zn}$ with respect to the control.

\section{Total suspended solids}

In particular, the TSS concentration of the control columns showed a seasonal variation along with the seasonal variation in water temperatures typical of conventional anaerobic lagoons (Figure $3 \mathrm{~A}$ and $\mathrm{B}$ ). Because of the particulate organic carbon $(\mathrm{C})$ content in wastewater, TSS concentrations in conventional anaerobic lagoons usually increase in winter, with the highest concentration found at the beginning of the spring, followed by a decrease in the summer, with the lowest concentration found at the beginning of the fall. In previous studies, similar seasonal fluctuations were observed in the concentration of other water quality parameters linked to the organic $\mathrm{C}$ content in lagoon liquid, such as chemical oxygen demand and volatile solids (Vanotti and Szogi, 2008); their decrease in concentration during summer and early fall was attributed to favorable water temperatures for microbial degradation of organic C (Westerman et al., 2010). As a result of the effective removal of more than $90 \%$ of the solids from the conventional lagoon inflows (Control - raw manure, Table 1), both SS and SS + NDN treatment showed a TSS trend different from the one described for the control. The concentration of TSS

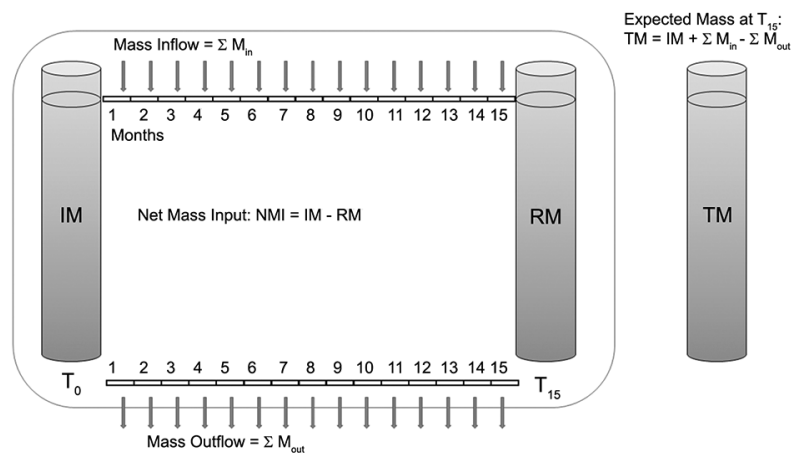

Figure 2 - Schematic diagram of the mass flow balance for phosphorus, copper, and zinc of the meso-scale lagoon columns. $\mathrm{IM}=$ Initial mass determined at $\mathrm{T}_{0} ; \mathrm{TM}=$ Total mass estimated at the end of the study $\left(\mathrm{T}_{15}\right)$; and $\mathrm{RM}=$ Recovered mass determined at the end of the 15-month study $\left(\mathrm{T}_{15}\right)$.

Table 2 - Initial and final mean composition and volume of liquid and sludge in the column experiment.

\begin{tabular}{|c|c|c|c|c|c|c|c|c|c|}
\hline \multirow{3}{*}{ Component } & \multirow{3}{*}{ Unit } & \multicolumn{2}{|c|}{ Initial Lagoon ( $\left.\mathrm{T}_{0}\right)$} & \multicolumn{6}{|c|}{ Final Lagoon $\left(\mathrm{T}_{15}\right)$} \\
\hline & & \multirow{2}{*}{ Liquid Fraction } & \multirow{2}{*}{ Sludge Fraction } & \multicolumn{3}{|c|}{ Liquid Faction $^{2}$} & \multicolumn{3}{|c|}{ Sludge Fraction } \\
\hline & & & & Control & SS & SS + NDN & Control & SS & $\mathrm{SS}+\mathrm{NDN}$ \\
\hline $\mathrm{TSS}^{1}$ & $m g L^{-1}$ & 240 & 40,900 & $480 a^{3}$ & $223 b$ & $100 \mathrm{c}$ & $64,925 \mathrm{a}$ & $73,750 \mathrm{a}$ & $81,750 \mathrm{a}$ \\
\hline TP & $m g L^{-1}$ & 40 & 1,406 & $83 a$ & $58 \mathrm{~b}$ & $60 \mathrm{~b}$ & 4,953 a & $5,479 a$ & $6,133 \mathrm{a}$ \\
\hline SRP & $m g L^{-1}$ & 42 & 95 & 81 a & $54 \mathrm{~b}$ & $58 b$ & $102 \mathrm{a}$ & $93 a$ & $91 \mathrm{a}$ \\
\hline $\mathrm{Cu}$ & $m g L^{-1}$ & 0.2 & 65 & $0.68 \mathrm{a}$ & $0.06 \mathrm{~b}$ & $0.11 \mathrm{c}$ & $211 \mathrm{a}$ & $226 a$ & $245 a$ \\
\hline $\mathrm{Zn}$ & $m g L^{-1}$ & 0.4 & 88 & $1.17 \mathrm{a}$ & $0.37 b$ & $0.31 \mathrm{c}$ & $307 a$ & $327 a$ & $343 a$ \\
\hline pH & & 8.15 & 7.69 & $8.0 \mathrm{a}$ & $8.2 \mathrm{a}$ & $8.4 \mathrm{a}$ & $7.60 \mathrm{a}$ & $7.84 \mathrm{a}$ & $8.21 \mathrm{a}$ \\
\hline Volume & L & 32.2 & 4.6 & 29.8 & 32.3 & 33.2 & $7.0 \mathrm{a}$ & $4.5 \mathrm{ab}$ & $3.6 \mathrm{~b}$ \\
\hline
\end{tabular}

${ }^{1}$ TSS = total suspended solids; TP = total phosphorus; SRP = soluble reactive phosphorus; ${ }^{2}$ SS, enhanced solid-liquid separation; SS + NDN, enhanced solid-liquid separation plus biological nitrogen; ${ }^{3}$ Data are the average of two lagoon columns per pretreatment; means within a row (liquid or sludge fraction) followed by the same letter are not significantly different $(p>0.05)$. 

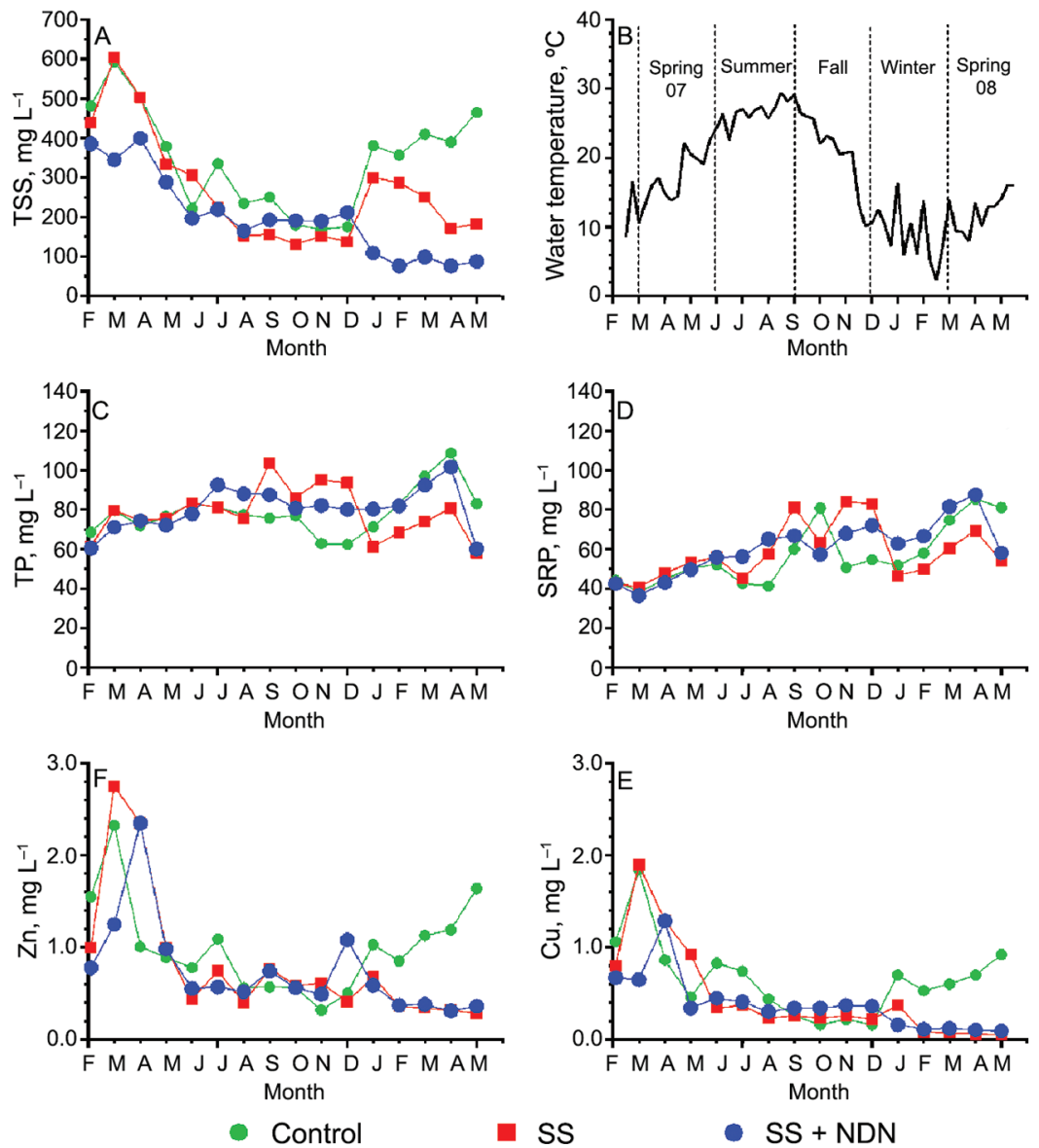

Figure 3 - Changes in concentration and temperature in the liquid of columns during the 15-month study: A: total suspended solids (TSS); B: lagoon water temperature; C: toal phosphorus (TP); D: soluble reactive phosphorus (SRP); E: copper (Cu); and F: zinc (Zn). Each data point is the monthly average of two replicates. Values at the end of the study are summarized in Table 2. TSS, total suspended solids; SS, enhanced solid-liquid separation; SS + NDN, enhanced solid-liquid separation plus biological N.

declined continuously from the beginning to the end of the study, with the decline being more prominent in the $\mathrm{SS}+\mathrm{NDN}$ than in the SS pretreatment (Figure 3A). At the end of the study $\left(\mathrm{T}_{15}\right)$, the TSS concentrations in the liquid fraction of the columns were significantly lower than the control for both SS and SS + NDN pretreatments (Table 2). Thus, the final TSS concentrations were $53 \%$ and $79 \%$ lower than the control for the SS and the SS + NDN pretreatments, respectively.

\section{Total $P$ and soluble reactive $P$}

In North Carolina, swine lagoon liquid have a wide range (60 - $130 \mathrm{mg} \mathrm{L}^{-1}$ ) of TP concentrations (Bicudo et al., 1999), and a range of $15-133 \mathrm{mg} \mathrm{TP} \mathrm{L}^{-1}$ have been reported in another study for swine lagoons of finishing farms (Westerman et al., 2010). In our study, monthly mean TP concentrations $\left(62-109 \mathrm{mg} \mathrm{L}^{-1}\right)$ for the control lagoon were within the TP ranges reported for North Carolina swine farms. As shown in Figure $3 \mathrm{C}$, the TP and SRP concentrations in the liquid fraction along the 15-month of our study were variable but did not have a consistent seasonal trend like TSS for the control or any of the two pretreatments. Moreover, the TP concentration range of the SS pretreatment (58 - 104 $\mathrm{mg} \mathrm{L}^{-1}$ ) and the SS + NDN pretreatment (60-102 mg $\mathrm{L}^{-1}$ ) were somewhat similar to the control (Figure 3C). Even though SS reduced TP in the inflow by $71 \%$ and SS + NDN reduced TP by $84 \%$ compared to the control, SRP was removed from the lagoon inflow only by $15 \%$ and $28 \%$ with SS and SS + NDN, respectively (Table 1). At the end of the 15-month $\left(\mathrm{T}_{15}\right)$ study, both pretreatments showed significant reductions of TP and SRP concentrations compared to the control (Table 2). However, mean monthly concentrations of both TP and SRP in the liquid fraction were all negatively correlated with TSS for either the SS or the SS + NDN pretreatment (Table 3). These negative correlation results suggest that even though the SS and SS + NDN pretreatments reduced $\mathrm{TP}$ and SRP in the influent, dissolution of $\mathrm{P}$ from the sludge into the overlying lagoon liquid sustained the TP and SRP concentrations levels somewhat similar to the control (Figure 3C and D). Further reduction of P levels 
Table 3 - Linear correlation coefficients ( $r$ ) of monthly concentration of total suspended solids (TSS) versus total phosphorus (TP), soluble reactive phosphorus (SRP), $\mathrm{Cu}$, and $\mathrm{Zn}$ in the liquid of the 15 -month column study ( $n=16$ ) of the control, enhanced solidliquid separation (SS), and enhanced solid-liquid separation plus biological nitrogen (SS + NDN) treatments.

\begin{tabular}{lcccc}
\hline \multirow{2}{*}{ Treatment } & \multicolumn{4}{c}{ Parameters } \\
\cline { 2 - 5 } & TP & SRP & Cu & Zn \\
\hline Control & 0.352 & -0.160 & $0.841^{*}$ & $0.897^{*}$ \\
SS & $-0.506^{*}$ & $-0.731^{*}$ & $0.891^{*}$ & $0.852^{*}$ \\
SS + NDN & $-0.774^{*}$ & $-0.872^{*}$ & $0.885^{*}$ & $0.786^{*}$
\end{tabular}

${ }^{*}$ Indicates $r$ is statistically different from $0(p<0.05)$; otherwise, $r$ is not significantly different from 0 .

in the lagoons' influent can be achieved by including a $\mathrm{P}$ removal process in the pretreatment (Szogi and Vanotti, 2009). Addition of a $\mathrm{P}$ removal treatment module after SS + NDN has been shown to reduce both the TP (38 $\%)$ and SRP (42\%) compared to their initial concentration levels in the liquid of anaerobic lagoon receiving pretreated influents (Vanotti and Szogi, 2008).

\section{Total $\mathrm{Cu}$ and $\mathrm{Zn}$}

With solid-liquid separation, effective removal of $\mathrm{Cu}$ and $\mathrm{Zn}(>87 \%)$ in the liquid fraction has been previously reported (Vanotti et al., 2009; Sommer et al., 2015). In our study, $\mathrm{Cu}$ and $\mathrm{Zn}$ concentrations in the inflow were reduced compared to the control by $89 \%$ with the SS, and $99 \%$ with the SS + NDN pretreatment (Table 1). In North Carolina, conventional lagoons in finishing farms have a wide range of concentrations of $\mathrm{Cu}\left(0.12-2.62 \mathrm{mg} \mathrm{L}^{-1}\right)$ and $\mathrm{Zn}\left(0.28-13.2 \mathrm{mg} \mathrm{L}^{-1}\right)$ because of varying levels in $\mathrm{Cu}$ and $\mathrm{Zn}$ included in the animal feed (Westerman et al., 2010). In our study, the control lagoon had concentration levels in the lower end of $\mathrm{Cu}\left(0.7 \mathrm{mg} \mathrm{L}^{-1}\right)$ and $\mathrm{Zn}\left(1.2 \mathrm{mg} \mathrm{L}^{-1}\right)$ reported for North Carolina lagoons (Table 2). The trend of monthly mean $\mathrm{Cu}$ and $\mathrm{Zn}$ concentrations in the liquid fraction are shown in Figure 3E and $\mathrm{F}$. The concentrations of $\mathrm{Cu}$ and $\mathrm{Zn}$ in the control column showed a seasonal variation consistent with the seasonal variation of TSS and water temperatures typical of conventional anaerobic lagoons (Figure 3A and B). However the trend of $\mathrm{Cu}$ and $\mathrm{Zn}$ in the liquid of the SS and the SS + NDN pretreatment columns were markedly different for the control (Figure 3E and F). The concentration of both $\mathrm{Cu}$ and $\mathrm{Zn}$ declined continuously from the beginning until the end of the study along with the decline in concentration in TSS. Unlike $\mathrm{P}$, there were strong positive correlations of the mean monthly concentrations of TSS with $\mathrm{Cu}$ and $\mathrm{Zn}$ concentrations in the liquid of both SS and SS + NDN pretreatment columns (Table 3). These results show that both SS and SS + NDN were effective in reducing $\mathrm{Cu}$ and $\mathrm{Zn}$ levels in lagoon liquid at the end of the 15-month study. Different from $\mathrm{P}$, once $\mathrm{Cu}$ and $\mathrm{Zn}$ are removed from the influent liquid, little dissolution of these elements occurs from the sludge into the liquid fraction.

\section{Effect of pretreatment on lagoon sludge}

The mean of TSS, TP, SRP, and $\mathrm{Cu}$ concentrations, $\mathrm{pH}$, and volume at the beginning and the end of the 15-month column study are shown in Table 2 for the sludge in the control and the two lagoon pretreatments. Typically, lagoon liquid has lower concentrations of most water quality parameters than the lagoon sludge (Bicudo et al., 1999). With the exception of $\mathrm{pH}$, similar trends were found in our study with lower concentrations of TSS, TP, $\mathrm{SRP}, \mathrm{Cu}, \mathrm{Zn}$ in the lagoon liquid than in the lagoon sludge (Table 2). Unlike the lagoon liquid, the concentration of all chemical parameters determined in the sludge were not different between treatments $(p>0.05)$ because the source of sludge added to the columns at the beginning of the experiment was a lagoon with a legacy of accumulating sludge for over 10 years of operation. However, the average sludge volumes of both pretreatments were different from the control at the end of the 15-month study $\left(\mathrm{T}_{15}\right.$, Table 2): $7.0 \mathrm{~L}$ in the control lagoon, $4.5 \mathrm{~L}$ in the $\mathrm{SS}$, and 3.6 in the SS + NDN $(p<0.05)$. These differences in sludge volume resulted in volumes of SS and SS $+\mathrm{NDN}$ that were $35 \%$ and $50 \%$, respectively, less than the sludge volume of the control. The TP, SRP, $\mathrm{Cu}$, and $\mathrm{Zn}$ concentrations and sludge volumes were used to estimate their respective mass flows for each treatment, which are further discussed in the following section.

\section{Mass flow balance}

The mass flow balance is an important part of the study for understanding the effect of pretreatment on the dynamics of $\mathrm{P}, \mathrm{Cu}$, and $\mathrm{Zn}$ in anaerobic lagoons. In an anaerobic lagoon environment, $\mathrm{P}, \mathrm{Zn}$, and $\mathrm{Cu}$ were considered conservative elements in the mass balance because they do not contribute to gaseous mass losses like non-conservative elements such as N (Szogi and Vanotti, 2014). The mass flow balances adequately determined the effect of the control and the SS and SS + NDN pretreatments on $\mathrm{TP}, \mathrm{Cu}$ and $\mathrm{Zn}$ buildup in the lagoon columns (Table 4). In the last column of Table 4 , the percent mass recovery efficiency is presented for all mass flow balances. High mass recovery efficiencies (TM/RM $>87 \%$ ) indicate that the total elemental mass expected at the end of the study (estimated from average monthly mass records) was consistent with the final elemental mass recovered. Overall, results in Table 4 reveal a build up of $\mathrm{P}, \mathrm{Cu}$ and $\mathrm{Zn}$ mass in the control columns loaded with untreated liquid manure during the 15-month period compared to the initial mass when comparing $\mathrm{RM}$ versus IM. However, the continuous high-rate removal of solids with the SS and the SS + NDN pretreatments reduced the overall accumulation of $\mathrm{P}, \mathrm{Cu}$ and $\mathrm{Zn}$ in the pretreated lagoon columns (Table 4). The net mass input (NMI) of P (Table 4), $\mathrm{Cu}$ and $\mathrm{Zn}$ during the 15-month study was estimated as the difference between the initial mass and total mass accumulated at the end of the study (RM - IM). Compared to the control, the NMI during the study declined in the lagoon columns which received both pretreatments: the TP net input declined $79 \%$ with 
SS, and $100 \%$ with SS + NDN; the Cu NMI declined $91 \%$ with SS, and $98 \%$ with SS + NDN; and the Zn NMI declined $91 \%$ with SS, and $97 \%$ with SS + NDN. Therefore, these reductions in net inputs of $\mathrm{P}, \mathrm{Cu}$, and
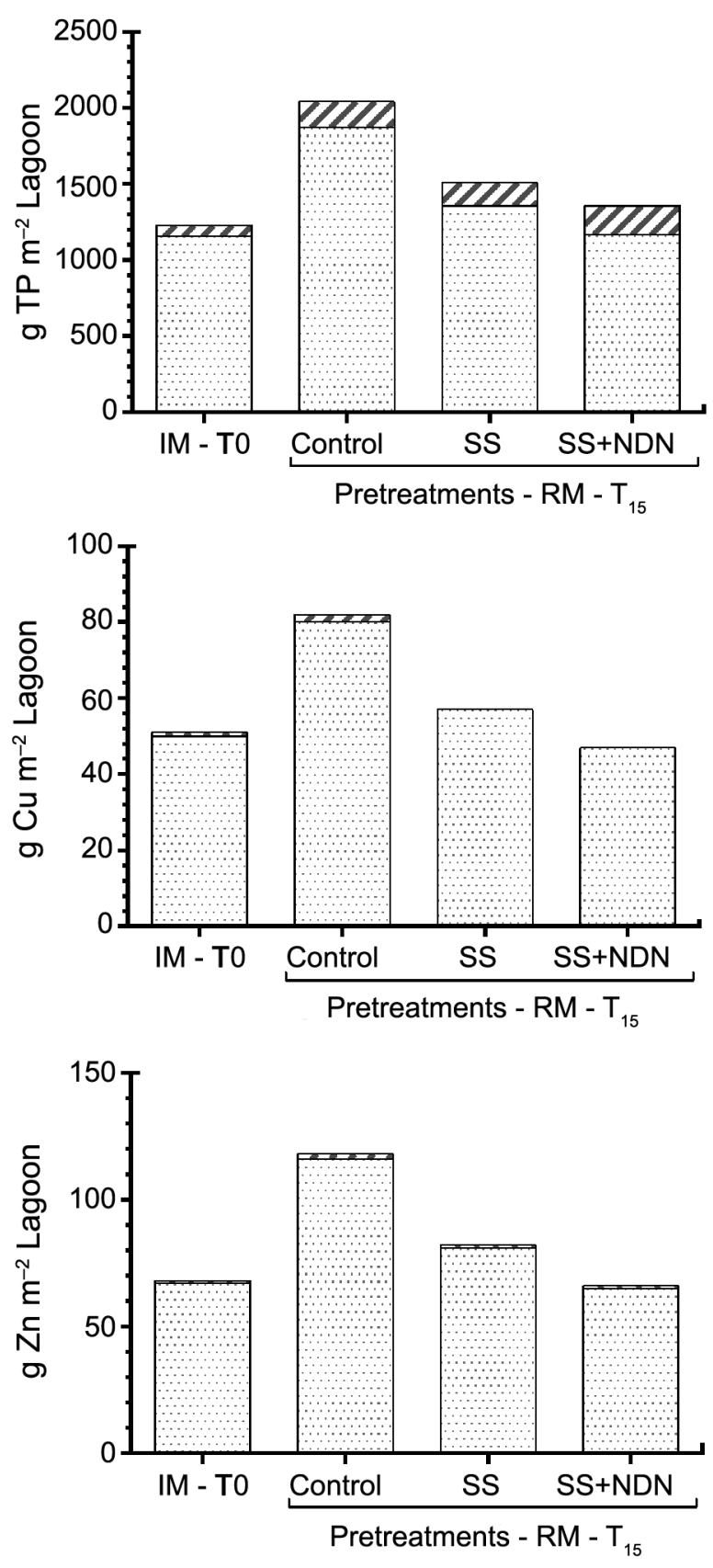

2 Liquid

Sludge

Figure 4 - Mass of phosphorus, copper, and zinc per lagoon surface area at the beginning of the study $\left(\mathrm{IM}-\mathrm{T}_{0}\right)$ and recovered at the end of the 15-month study (RM $-\mathrm{T}_{15}$ ) in the lagoon liquid and sludge. SS, enhanced solid-liquid separation; SS + NDN, enhanced solidliquid separation plus biological $\mathrm{N}$.
Zn resulted in smaller recovered masses (RM) in pretreated columns than in the control (Table 4). The RM of TP were $26 \%$ and $34 \%$ less than the control with SS and SS + NDN pretreatments, respectively. The RM of $\mathrm{Cu}$ were less than the control by $30 \%$ with SS and $42 \%$ with SS + NDN. The RM of $\mathrm{Zn}$ reduction with respect to the control followed a trend to that of $\mathrm{Cu}$, with RM 31 $\%$ and $44 \%$ less than the RM of the control with SS and $\mathrm{SS}+\mathrm{NDN}$, respectively.

As part of the mass flow balance, the mass of $\mathrm{P}$, $\mathrm{Cu}$, and $\mathrm{Zn}$ in the liquid and sludge fractions were determined, and expressed per lagoon surface area as shown in Figure 4. The mass of $\mathrm{P}, \mathrm{Cu}$, and $\mathrm{Zn}$ per square meter of lagoon $\left(\mathrm{g} \mathrm{m}^{-2}\right)$ in the liquid fraction at the beginning of the study (IM $\mathrm{T}_{0}$ ) and recovered at the end of the 15-month study (RM) for each pretreatment were a small fraction of the total mass (liquid + sludge) fractions in the lagoon columns $\mid<16 \%$ for $\mathrm{P}$ and $<3 \%$ for $\mathrm{Cu}$ or $\mathrm{Zn})$. Compared to the sludge fraction that made $>84 \%$ of the total mass of P and > $97 \%$ of the total mass of $\mathrm{Cu}$ or $\mathrm{Zn}$ in the columns, the SS and SS + NDN pretreatments reduced $\mathrm{P}, \mathrm{Cu}$ and $\mathrm{Zn}$ mass accumulation as compared to the control. The mass reduction of $\mathrm{Cu}$ and $\mathrm{Zn}$ with the SS + NDN pretreatment was such that it stopped the accumulation of $\mathrm{Cu}$ and $\mathrm{Zn}$ in the sludge. This is illustrated in Figure 4 where the initial sludge mass of $\mathrm{Cu}$ and $\mathrm{Zn}\left(\mathrm{IM}-\mathrm{T}_{0}\right)$ for the SS + NDN pretreatment were almost the same as their masses found in the sludge recovered at the end of the study $\left(\mathrm{RM}-\mathrm{T}_{15}\right)$.

In summary, the results on concentration changes of $\mathrm{P}, \mathrm{Cu}$, and $\mathrm{Zn}$, and mass flow analysis of our lagoon column study show that SS and SS + NDN pretreatments differ significantly in their efficiency in reducing $\mathrm{P}, \mathrm{Cu}$ and $\mathrm{Zn}$ in anaerobic lagoons. Although SS and SS + NDN pretreatments were less effective in reducing soluble $\mathrm{P}$ in lagoon liquid, both pretreatments stopped the accumulation of $\mathrm{P}$ in the sludge fraction, which comprises most of the mass of $\mathrm{P}$ in a lagoon. The significant decrease in $\mathrm{Cu}$ and $\mathrm{Zn}$ concentrations in the influent was also a major factor in reducing their concentrations in the lagoon liquid and stop their accumulation in the lagoon sludge. Because conventional anaerobic lagoons require sludge management (Schmidt, 2013), the SS treatment using enhanced flocculation would reduce the frequency of sludge removal from lagoons retrofitted with this technology, as well as the land requirements and transportation for sludge disposal. The SS + NDN can offer similar benefits as SS in terms of sludge management with the added advantage of providing biological $\mathrm{N}$ treatment followed by $\mathrm{P}$ recovery with the potential for using treated water low in $\mathrm{N}, \mathrm{P}, \mathrm{Cu}$ and $\mathrm{Zn}$ to irrigate cash crops.

\section{Acknowledgement}

Mention of trade names or commercial products in this article is solely for the purpose of providing specific information and does not imply recommendation or en- 
Table 4 - Total initial mass, mass flow, and recovered mass of $\mathrm{P}, \mathrm{Cu}$, and $\mathrm{Zn}$ for the treatments applied in the lagoon column experiment (liquid + sludge).

\begin{tabular}{|c|c|c|c|c|c|c|c|c|}
\hline Element & Lagoon Pretreatment ${ }^{1}$ & $\mathrm{IM}^{2}$ & $M_{\text {in }}$ & $M_{\text {out }}$ & NMI & TM & RM & TM/RM \\
\hline & & & g Columr & & & & & \\
\hline \multirow[t]{3}{*}{$P$} & Control & 22.6 & 14.7 & 2.1 & 15.0 & 35.2 & 37.6 & 94 \\
\hline & SS & 22.6 & 4.7 & 2.1 & 5.2 & 25.2 & 27.8 & 91 \\
\hline & $\mathrm{SS}+\mathrm{NDN}$ & 22.6 & 1.8 & 2.2 & 2.4 & 22.2 & 25.0 & 89 \\
\hline \multirow[t]{3}{*}{$\mathrm{Cu}$} & Control & 0.93 & 0.47 & 0.02 & 0.56 & 1.39 & 1.49 & 93 \\
\hline & SS & 0.93 & 0.05 & 0.01 & 0.11 & 0.97 & 1.04 & 93 \\
\hline & $S S+N D N$ & 0.93 & 0.003 & 0.01 & 0.00 & 0.92 & 0.86 & 107 \\
\hline \multirow[t]{3}{*}{$\mathrm{Zn}$} & Control & 1.25 & 0.72 & 0.03 & 0.93 & 1.94 & 2.18 & 89 \\
\hline & SS & 1.25 & 0.08 & 0.02 & 0.25 & 1.31 & 1.50 & 87 \\
\hline & $\mathrm{SS}+\mathrm{NDN}$ & 1.25 & 0.004 & 0.02 & 0.04 & 1.23 & 1.21 & 102 \\
\hline
\end{tabular}

${ }^{1} \mathrm{SS}$, enhanced solid-liquid separation; $\mathrm{SS}+\mathrm{NDN}$, enhanced solid-liquid separation plus biological nitrogen; ${ }^{2} \mathrm{M}=$ Initial mass $\left(\mathrm{T}_{0}\right)$; $\mathrm{M}_{\text {in }}=\mathrm{Mass}_{\mathrm{inflow}} \mathrm{M}_{\text {out }}=\mathrm{MasS}$ outflow; $\mathrm{NMI}=$ Net mass input $[\mathrm{NMI}=\mathrm{IM}-\mathrm{RM}] ; \mathrm{TM}=$ Total mass expected at the end of the study $\left[\mathrm{TM}=\mathrm{IM}+\mathrm{M}_{\text {in }}-\mathrm{M}_{\text {out }}\right.$; RM $=\mathrm{Recovered}$ mass at the end of the study, TM/RM = Recovery efficiency expressed in percentage.

dorsement by the U.S. Department of Agriculture. This research was part of USDA-ARS National Program 214: Manure and By-Product Utilization; ARS Project 608213630-005-00D "Innovative Animal Manure Treatment Technologies for Enhanced Environmental Quality."

\section{References}

American Public Health Association [APHA]. 1998. Standard Methods for Examination of Water and Wastewater. 20ed. APHA, Washington, DC, USA.

Barker, J.C. 1996. Swine Production Facility Manure Management: Pit-Recharge-Lagoon Treatment. North Carolina Cooperative Extension Service, Raleigh, NC, USA. (Publication EBAAE-128-88).

Bicudo, J.R.; Safley Jr., L.M.; Westerman, P.W. 1999. Nutrient content and sludge volumes in single-cell recycle anaerobic lagoons in North Carolina. Transactions of the American Society of Agricultural Engineers 42: 1087-1093.

Cahoon, L.B.; Ensign, S.H. 2004. Spatial and temporal variability in excessive soil phosphorus levels in eastern North Carolina. Nutrient Cycling in Agroecosystems 69:11-125.

Hjorth, M.; Christensen, K.V.; Christensen, M.L.; Sommer, S.G. 2010. Solid-liquid separation of animal slurry in theory and practice: a review. Agronomy for Sustainable Development 30: 153-180.

Nelson, N.O.; Parsons, J.E.; Mikkelsen, R.L. 2005. Field-scale evaluation of phosphorus leaching in acid sandy soils receiving swine waste. Journal of Environmental Quality 34: 2024-2035.

Novak, J.M.; Szögi, A.A.; Watts, D.W. 2008. Copper and zinc accumulation in sandy soils and constructed wetlands receiving pig manure effluent applications. p. 45-54. In: Schlegel, P.; Durosoy, S.; Jongbloed, A.W., eds. Trace elements in animal production systems. Wageningen Academic Publishers, Wageningen, Netherlands.

Novak, J.M.; Watts, D.W.; Hunt, P.G.; Stone, K.C. 2000. Phosphorus movement through a coastal plain soil after a decade of intensive swine manure application. Journal of Environmental Quality 29: 1310-1315.
Peters, J. 2003. Recommended Methods of Manure Analysis (A3769). University of Wisconsin, Madison, WI, USA.

Schmidt, A.M. 2013. Sludge Management for Anaerobic Lagoons and Runoff Holding Ponds. University of Nebraska, Lincoln, NE, USA.

Sommer, S.G.; Hjorth, M.; Leahy, J.J.; Zhu, K.; Christel, W.; Sorensen, C.G.; Sutaryo. 2015. Pig slurry characteristics, nutrient balance and biogas production as affected by separation and acidification. Journal of Agricultural Science 153: 177-191.

Szogi, A.A.; Vanotti, M.B. 2009. Removal of phosphorus from livestock effluents. Journal of Environmental Quality 38: 576586.

Szogi, A.A.; Vanotti, M.B. 2014. Water quality and nitrogen mass loss from anaerobic lagoon columns receiving pretreated influent. Journal of Environmental Quality 43: 1219-1226.

Szogi, A.A.; Vanotti, M.B.; Ro, K.S. 2015. Methods for treatment of animal manures to reduce nutrient pollution prior to soil application. Current Pollution Reports 1: 47-56.

Vanotti, M.B.; Szogi, A.A. 2008. Water quality improvements of wastewater from confined animal feeding operations after advanced treatment. Journal of Environmental Quality 37: S86-S96.

Vanotti, M.B.; Szogi, A.A.; Hunt, P.G. 2005. Wastewater treatment system. United States Patent No. 6,893,567. U.S. Patent and Trademark Office, Washington, DC, USA.

Vanotti, M.B.; Szogi, A.A.; Millner, P.D.; Loughrin J.H. 2009. Development of a second-generation environmentally superior technology for treatment of swine manure in the USA. Bioresource Technology 100: 5406-5416.

Westerman, P.W.; Ogejo, J.A.; Grabow, G.L. 2010. Swine anaerobic lagoon nutrient concentration variation with season lagoon level, and rainfall. Applied Engineering in Agriculture 26: $147-152$. 